\section{Race equality in mental healthcare: is routine data collection adequate ${ }^{+}$}

Peter Aspinall's article (Aspinall, 2006) provides an excellent review of the current status of information relating to race and mental health. It is difficult to see how healthcare organisations, and those with responsibility for data prioritisation, definition, collection and dissemination, can be fully compliant with the Race Relations (Amendment) Act 2000, or deliver on the Department of Health's policies relating to mental health and reduced health inequalities, in the absence of data to support basic functions relating to race equality such as health needs assessments, monitoring access to services and treatments, and outcomes. In February 2007 the Commission for Race Equality announced an investigation into whether the Department of Health is meeting its race equality duties (Commission for Race Equality, 2007), and a subsequent crossgovernment equalities review by the Cabinet Office noted the lack of equality dimensions (other than age and gender) in health data for equality monitoring (Cabinet Office, 2007).

I would like to make some specific points regarding Dr Aspinall's article. First, he rightly notes that ethnicity recording for in-patients became mandatory in 1995. However, currently, not only is it not mandatory for patients treated out of hospital, there is a Data Set Change Notice (DSCN) in place that bars healthcare organisations from transferring information about the ethnicity of these patients (NHS Information Standards Board, 2005). This probably reflects a cautious interpretation of the Data Protection Act. The Healthcare Commission has drawn the attention of the Information Centre and Department of Health to this historical anomaly, and it has formally sponsored a proposal to the Information Centre that ethnicity coding be made mandatory in all commissioning data-sets (CDS), i.e. out-patients and A\&E patients, and the Mental Health Minimum Data Set (MHMDS) (for all patients, not just in-patients). This is now going through the approval process, but will take the customary time to implement.

Second, in order to drive improvements in ethnicity coding in national data-sets (those where ethnicity coding is mandated), the Healthcare Commission, and its predecessor the Commission for Health Improvement, has included indicators on ethnicity coding levels in its annual performance assessments of NHS organisations since 2003. We believe that this has contributed significantly to the steady improvement in coding over recent years,

${ }^{+}$See also pp. $350-357$, this issue. Ed. for example valid coding in the Hospital Episode Statistics (HES) has increased from $64 \%$ in 2002/03 to almost $80 \%$ in 2004/05.

Third, Aspinall notes the incomplete recording of ethnicity in the HES and MHMDS, and the urgent need for this to improve. It is important to add some qualifiers: (a) there will always be some patients who do not wish to give their ethnicity; and (b) in the MHMDS, ethnicity coding is over $90 \%$ for in-patients; for other patients it is about $60 \%$, attributable probably to my first point above. The fact that mental health trusts are recording and transmitting this information at all for patients not admitted to hospital is to be commended, given that it is contrary to current official guidance.

Fourth, the Healthcare Commission is the regulator for all healthcare in England, both NHS and the independent sector. It has noted to both the Department of Health and the Information Centre that data-sets applicable to the NHS need to extend to independent sector providers of care to NHS patients, to support compliance with equality legislation (among other reasons that make this information important). The Commission is working with these agencies to support developments in this direction, although contractual, information technology and resource issues may make this a slower process than we would want.

Finally, the lack of primary care data by ethnicity is a notable gap in information about mental health service users. Hopefully this will be addressed in due course via the Connecting for Health initiative.

Aspinall, P. J. (2006) Informing progress towards race equality in mental healthcare: is routine data collection adequate? Advances in Psychiatric Treatment, 12, 141-151.

Cabinet Office (2007) Fairness and Freedom: The Final Report of the Equalities Review. TSO (The Stationery Office).

Commission for Race Equality (2007) 'CRE announces investigation into Department of Health for failings on race equality'. Commission for Race Equality. http:/ / www.cre.gov. uk/Default.aspx.LocID-0hgnew0qf.RefLocID-0hg00900c002. Lang-EN.htm

NHS Information Standards Board (2005) Data Set Control Change Procedure (DSC Notice: 32/2004). NHS Information Authority. http://www.connectingforhealth.nhs.uk/dscn/ dscn2004/322004.pdf

Veena S. Raleigh Lead, Methods and Research, Informatics, Healthcare Commission, Finsbury Tower, 103-105 Bunhill Row, London EC1Y 8TG, UK. Email: veena.raleigh@ healthcarecommission.org.uk. Reader, Postgraduate Medical School, University of Surrey

doi: 10.1192/apt.13.5.394

\section{Spirituality and psychiatry: conflicting values?}

Larry Culliford's (2007) article stresses the subjective and uniquely personal character of spiritual experience. We agree. Psychiatry's tendency to privilege the objective over the subjective has 